\title{
Helmet Wearing Among Commercial Motorcyclist in Brazzaville (Congo): Knowledge, Attitude and Prevalence
}

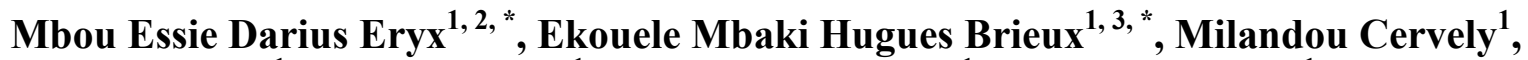 \\ Matini Prefina ${ }^{1}$, Engambe Peya ${ }^{1}$, Baloumbou Ndzaba ${ }^{1}$, Ngoyomi Ryschel ${ }^{1}$, Ntsiba Honore ${ }^{1}$, \\ Ibara Jean-Rosaire ${ }^{1}$
}

${ }^{1}$ Faculty of Health Sciences, Marien Ngouabi University, Brazzaville, Congo Rep

${ }^{2}$ Directorate of Primary Health Care, Ministry of Health and Population, Brazzaville, Congo Rep

${ }^{3}$ Neurosurgery Department, Brazzaville University Hospital, Brazzaville, Congo Rep

Email address:

eryxdarius40@gmail.com (M. E. D. Eryx), hugues.ekouele-mbaki@umng.cg (E. M. H. Brieux)

${ }^{*}$ Corresponding author

\section{To cite this article:}

Mbou Essie Darius Eryx, Ekouele Mbaki Hugues Brieux, Milandou Cervely, Matini Prefina, Engambe Peya, Baloumbou Ndzaba, Ngoyomi Ryschel, Ntsiba Honore, Ibara Jean-Rosaire. Helmet Wearing Among Commercial Motorcyclist in Brazzaville (Congo): Knowledge, Attitude and Prevalence. World Journal of Public Health. Vol. 5, No. 3, 2020, pp. 60-65. doi: 10.11648/j.wjph.20200503.13

Received: August 5, 2020; Accepted: August 20, 2020; Published: September 3, 2020

\begin{abstract}
Transport on motorcycles has grown and is widespread in Congo (Brazzaville) and several sub-Saharan Africa countries; leading to a growing incidence of traffic road injuries and fatalities. The effectiveness of helmet wearing as preventing is founded out and the laws on its promotion exist, but its prevalence remains low. In order to make commercial motorcyclists and their passengers aware of the importance of wearing a safety helmet and contribute to promoting, the study aims to determine the prevalence, the knowledge, and attitude of helmet use and attitude among motorcycle taxi drivers in Brazzaville. We performed a descriptive cross-sectional mixed-method study, both quantitative and qualitative data were collected and analyzed. A total of 241 commercial motorcyclists were interviewed in their station point, near the market located in areas of the north of Brazzaville downtown. All were male with an average age of $28.6 \pm 7.1$ years, $65.1 \%(157 / 241)$ had a previous motorcycle accident and none had a driving certificate. Ninety-one point three of the percentage had a "good level of knowledge on the helmet, their attitudes towards safety helmets use were favorable among $95.4 \%(230 / 241)$. Only $40.3 \%(97 / 241)$ of drivers wore the helmet, slightly linked to the history of police sanction $(\mathrm{p}<0,05)$. The study carried out a high level of knowledge, a favorable attitude towards the use of safety helmets contrasted with the low prevalence of helmet use, exposing drivers and passengers to the risk of fatal head injuries. The promotion of the wearing of safety helmets should take into account the emergence of this type of public transport, in order to address awareness and coercive actions to them.
\end{abstract}

Keywords: Commercial Motorcyclists, Road Traffic Injury, Helmet Use, Knowledge-Attitude, Prevalence, Congo-Brazzaville

\section{Introduction}

Public or individual transport on motorcycles has grown and is widespread in several countries in sub-Saharan Africa. This is the case in Nigeria [1], Benin where they represented up to $83 \%$ of motorized vehicles in 1981 [2], Ghana where their number rose by $292 \%$ between 2000 and 2008 [3] and Kenya where the number rose from 57,000 in 2005 to 514,000 in 2011 representing $36.1 \%$ of vehicles [4]. In Brazzaville, Congo, this type of transport has recently emerged. It is known as "motorcycle taxi" or "Jakarta", named after the Indonesian capital where these motor bikes are manufactured.

The increase in motorcycle transport has led to a growing incidence of road accidents. In Kenya, for example, accidents involving motorcycles doubled between 2004 and 2009 with an annual increase of $29 \%$ [5]. Head injuries and fatalities are then on the rise [6-8]. These accidents represent the third leading cause of death from road traffic accidents in Asia, a significant share in developed countries and a growing share in Africa. Head injuries account for $88.8 \%$ of all deaths [9]. 
In Congo, despite the lake of official statistics, the rate of accident involve motor bicycles is increasing. In the same period, the epidemiology of head trauma victims admitted to Brazzaville University Hospital reveals that $39.7 \%$ were drivers or passengers of motor bicycles [10].

According to several studies, not wearing a safety helmet is strongly associated with serious cerebral complications in the event of a motorcycle accident, and compliance with the wearing of a helmet correlates with a reduction in these complications $[11,12]$. Some studies report up to a $69 \%$ reduction in head injuries and a $42 \%$ reduction in the number of deaths $[13,14]$. Motorcyclist who did not wear a helmet have a 40 times greater risk of head injury in the event of an accident than those who did wear a helmet [7]. In order to make motorcyclists and their passengers aware of the importance of wearing a safety helmet, the study aims to determine the prevalence, the knowledge and attitude toward helmet use among motorcycle taxi drivers in Brazzaville.

\subsection{Statement of the Problem}

The effectiveness of helmet wearing is founded out. In African sub-Saharan countries who have the highest rate of death due to traffic injuries, the rates of helmet wearing remains low, despite the laws on helmet use. In Congo the rate of death due to traffic injury is 17 per 100.000 persons, the lake of data on helmet wearing is a major issue for planning the preventing interventions promoting helmet wearing. The motorcyclists "moto taximen" constitute the major target because they also involve the passenger's lives.

\subsection{Objectives of the Study}

\subsubsection{General Objective}

The study aimed to contribute to promote helmet wearing and reduce the fatalities while traffic injury involved motorcyclist, by implanting the campaign of sensibilization.

\subsubsection{Specific Objectives}

The study aimed to:

Describe the "motorcyclist" socio-demographics characteristics. Assess the knowledge level on helmet utility.

Assess the attitude to helmet wearing.

Determine the helmet wearing prevalence.

\subsection{Significance of the Study}

The traffic injury involved the motorcyclist is the most public health concern due to brain trauma. Helmet use is an effective intervention, but there is paucity of data on helmet wearing among motorcyclist in Brazzaville. The study seeks finding out the prevalence of helmet wearing among motorcyclist and the possible factors which influence helmet use. As type of transport the motorcyclist involve also the passenger's lives. It will one of first study in this field.

Table 1. Helmet's knowledge level score.

\begin{tabular}{|c|c|c|c|}
\hline \multirow{2}{*}{ Proposal } & \multirow{2}{*}{ Correct answer } & \multicolumn{2}{|l|}{ Weitling } \\
\hline & & Yes/Did & No/Didnt'know \\
\hline Have you ever heard of biker protection devices? If yes, cite them & Had Cited & 2 & 0 \\
\hline How important is the safety helmet? & Head protection or safety & 2 & 0 \\
\hline Do you know a place of helmet sales?, if yes locate it & Had located correctly & 2 & 0 \\
\hline Give an average price of helmet & 5-15000FCFA & 2 & 0 \\
\hline Does the law or the police require the wearing of a safety helmet? & Yes & 2 & 0 \\
\hline
\end{tabular}

Interprétation:

Score $\geq 6=$ acceptable or good knowledge level.

Score $<6=$ unacceptable or poor knowledge level.

Table 2. Attitude score for wearing a safety helmet.

\begin{tabular}{llll}
\hline \multirow{2}{*}{ Proposal } & Assessment & Pondération \\
\cline { 3 - 4 } & Yes/no & Yes & No/didn't \\
\hline History of helmet wearing & Yes/no & 1 & 0 \\
Headset purchase history & yes /no/ dind't know & 1 & 0 \\
Opinon on police sanction & Yes /no & 0 & 0 \\
Refusal to wear a helmet & Yes /no/ didn't know & 4 & 2 \\
Decision to wear the helmet & & 0 \\
\hline
\end{tabular}

Interprétation:

Score $\geq 7=$ favorable attitude.

Score $<7=$ unfavorable attitude.

\section{Research Methodology}

\subsection{Conceptual Framework}

The independent variable were socio demographics characteristics as: age, sex, nationality, school level, belonging of motorcycle, existing of another job, history of motorcycle driving, history of traffic road injury, history of police sanction.

The dependent or outcome variables were: attitude to helmet wearing, and knowledge level on helmet.

\subsection{Study Setting}

The study took place in the motorcycle station near market located in areas of north of Brazzaville downtown: Mikalou, lycée Thomas Sankara, Kombo CNRTV and Soprogi.

\subsection{Study Population}

The motorcyclist who earn money by carrying person who is named "Moto-taximen". 


\subsubsection{Inclusion Criteria}

All motorcyclist present in site and who gave her verbal consent.

\subsubsection{Exclusion Criteria}

Non consent, or any file not completely filed.

\subsection{Research Design}

The design of study was a descriptive cross-sectional mixed-method, both quantitative and qualitative data were collected and analyzed. Qualitative date was a bout attitude which has scored from 0 to 9 (table 2). The knowledge level was scored from 0 to 10 (table 1 ).

\subsection{Sample Size Determination and Sampling Procedure}

The sample size couldn't determine previously, so the population of motorcyclist "moto-taximen" was not known yet. We opted for exhaustive recruitment of all "motorcyclist" consent being included.

\subsection{Data Collecting}

With close questionnaire we used "directive interview", a questionnaire was researcher administered. Sometimes he translated in Lingala (Congolese local language) for motorcyclist.

The date was collected between from February $7^{\text {th }}$ to $13^{\text {th }}$, 2020 (7 days).

\subsection{Pre-testing}

Pre-testing was done on 30 motorcyclists, six in each site, therefore the questionnaire was adapted.

\subsection{Variables Measurement}

\subsubsection{Dependent Variables}

The dependent variables for this study were:
Knowledge level on helmet utility and prevalence of helmet wearing. The level of knowledge was scored from 0 to 10 ; categorized in "poor level" and "good level" as shown in table 1.

Attitude to helmet wearing. It was scored from 0 to 7 . And categorized in "favorable" and "defavorable" as shown in table 2.

\subsubsection{Independent Variables}

The independents variables were:

Socio-demographics characteristics, length of time on the motorcycle,

Personal motorcycle accident history,

History of helmet wearing,

Headset purchase history.

Opinion on the strengthening of laws on helmet use. Did they approve the punishing offenders by police?

\subsection{Data Analysis}

Descriptive statistics were made by calculating frequencies, mean and standard deviation. The comparison of means was done using Student's t-test and the comparison of proportions was done using the KHI2. The significance threshold was set at $\mathrm{p}<0.05$. The data were sorted out, cleaned, categorized, coded, entered and analyzed on Epi info 7.2.2.6 software.

\section{Results}

\subsection{Characteristics of Sample}

A total of 253 drivers were contacted of which 241 (95\%) accepted maintenance and $13(5 \%)$ refused. The average age of the drivers was $28.6 \pm 7.1$ years, the average length of time on the motorcycle was 62.3 months and the average length of time in motorcycle taxi activity was 6.4 months; $65.1 \%$ $(157 / 241)$ had a previous motorcycle accident. The characteristics of the sample are detailed in Table 3.

Table 3. characteristics of sample.

\begin{tabular}{|c|c|c|}
\hline & $\mathbf{n}$ & $\%$ \\
\hline \multicolumn{3}{|l|}{ Observation site } \\
\hline Mikalou & 106 & 44 \\
\hline Lycée thomas-sankara & 57 & 23,7 \\
\hline Nkombo-esplanade CNRTV & 54 & 22,3 \\
\hline Soprogi & 24 & 10 \\
\hline \multicolumn{3}{|l|}{ Gender } \\
\hline Masculin & 240 & 99,6 \\
\hline \multicolumn{3}{|l|}{ Nationality } \\
\hline Congoleese & 228 & 94,6 \\
\hline Other & 13 & 5,4 \\
\hline \multicolumn{3}{|l|}{ Age range (years) } \\
\hline $17-26$ & 109 & 45,2 \\
\hline $27-36$ & 102 & 42,3 \\
\hline $37-46$ & 25 & 10,4 \\
\hline $47-56$ & 5 & 2,1 \\
\hline None & 16 & 6,64 \\
\hline $\mathrm{Cepe}^{\mathrm{a}}$ & 44 & 18,26 \\
\hline $\mathrm{Bepc}^{\mathrm{b}}$ & 103 & 42,74 \\
\hline $\mathrm{Bac}$ & 63 & 26,14 \\
\hline $\mathrm{Bac}+$ & 15 & 6,22 \\
\hline Another job & & \\
\hline
\end{tabular}




\begin{tabular}{lll}
\hline & $\mathbf{n}$ & \% \\
\hline Yes & 131 & 54,4 \\
No & 110 & 45,6 \\
Seniority in motorcycle riding $($ years) & \\
$0-4$ ans & & 60 \\
$5-10$ & 144 & 26,6 \\
$11-15$ & 64 & 9,2 \\
$16-+$ & 22 & 4,2 \\
Belonging to the motorcycle & 10 & 66 \\
Owner & 159 & 34 \\
Tenant & 82 & 65,1 \\
Road accident history & & \\
Yes & 157 & 34,9 \\
No & 84 & \\
\hline
\end{tabular}

$\mathrm{a}=$ elementary certificate, $\mathrm{b}=$ first cycle brevet. $\mu=$ one motorcyclist didn't give his seniority in riding.

\subsection{Level of Knowledge}

On the level of helmet knowledge, of the 241 drivers $91.3 \%$ had a "good level of knowledge" ( $\geq 6$ score). For knowledge of types of safety equipment, only the helmet was cited by $44 \%$, helmet and other accessories by $37.4 \%$, only other accessories by $2 \%$ and no equipment by $16.6 \%$. Specifically, about the helmet, $91 \%$ knew where it was purchased and $86 \%$ knew its price. The importance of the helmet was known by $81.3 \%$ (196/241). Finally, 93\% (224/241) of drivers knew that not wearing a helmet was punishable by law or the police.

\subsection{Attitudes to Helmet Wearing}

Attitudes towards the use of safety helmets were favorable among 95.4\% (230/241) and unfavorable among $4.6 \%(11 / 241)$ of motorcyclist, two of whom had explicitly refused to wear a helmet. A total of $95.5 \%$ (231/241) said they had already worn a safety helmet and $81 \%$ had already purchased one. Also 83.8\% (203/241) approved of the police crackdown on helmet use. The police's previous record of sanctioning by the police was investigated: $53.1 \%$ $(128 / 241)$ had already been fined with or without confiscation of a motorcycle, $16.2 \%$ with a simple warning and the remaining $30.7 \%$ had never been sanctioned. Of all the respondents $93.8 \%$ took the decision to buy and wear a helmet now or always.

\subsection{Prevalence of Helmet Wearing}

For the prevalence of helmet use: $59.7 \%$ (144/241) did not wear a helmet, $40.3 \%(97 / 241)$ wore a helmet or hung it on their motorcycle. The reason for the 144 not wearing a helmet was: discomfort for $1.4 \%(2 / 144)$, lack of money to buy one for $9.7 \%(14 / 144)$ and no reason for $88.9 \%(128 / 144)$ others. Helmet use was compared in the different modalities of school level, seniority in motorcycle riding, attitude towards helmet use, history of police sanction and motorcycle accident $(p=0,03$. Table 4$)$.

\section{Discussion}

In Congo public transport by motorcycle is illegal (Road Code of Economic and Monetary Community of Central Africa, art 52. EMCCA, 2001); it is also the case in Ghana where driving a motorcycle is reserved for private use. Wearing a safety helmet significantly reduces cerebral or cervical complications and deaths in motorcycle accidents [13-15]. Thus, several countries have laws making the wearing of a safety helmet mandatory. In Kenya, under the Traffic Act Rules (2012 Amendment) the offender is punished with a fine of 10,000 shillings (94.12 US dollars/ https://fr.coinmill.com/KES USD.html, updated on June, $22^{\text {th }}$ 2020). In Benin, Decree No. 72-113 of 27 April 1972, prescribing the compulsory wearing of helmets for drivers and passengers of two-wheeled vehicles and similar vehicles equipped with an internal combustion engine, as well as the Prefectural Enforcement Order: Year 2011 N²/_0321_/DEPATL-LIT/SG/SPAT (available at: https://www.24haubenin.info/?L-integralite-de-1-arrete) punish offenders with a fine and/or impoundment.

Our sample consisted only of adult males (Table 3 ). Its characteristics are very similar to those of the study by Fadekemi $O$ et al [16] where all respondents were adult males $(35.1 \pm 8.6$ years vs. $28.6 \pm$ years in our study), very few $(8.4 \%)$ had no education as in our study $(6.6 \%)$. The male gender was also dominant in the studies conducted in Ghana, where $86.5 \%$ to $88.8 \%$ were men and $74.1 \%$ were adults [17.18], and in Bachani A's study in Kenya, where $97.1 \%$ to $97.9 \%$ were men [15]. The educational level was higher in our country $(75.1 \%$ secondary school or higher) while in Kenya they were $42.2 \%$ to $52.1 \%$ secondary school or higher [15]. The level of knowledge about the safety helmet and its importance was overwhelmingly good (91.3\%) compared to that found by Bachani A [10] and the $20 \%$ reported by Fadekemi $\mathrm{O}$ [16]. In our case this may be due to a high level of literacy in Congo [19]. None of our respondents had a driving licence; in the Fadekemi $\mathrm{O}$ study in Nigeria $44.2 \%$ had less than one month's training. This explains why a large majority $(65.1 \%)$ had already had a motorcycle accident; this proportion was $46 \%$ in Fadekemi $\mathrm{O}$ [16].

Despite the existence of these restrictive laws and police sanctions reported by more than two thirds of our respondents $(69.3 \%)$, the findings show a low prevalence of helmet use in several African cities. In Ghana between $45.8 \%$ and $32.4 \%$ [17.18], in Kenya between $35.12 \%$ and $37.42 \%$ [15], in Nigeria 23.8\%; as an illustration, the tightening of 
the "Traffic Act Rules" has not significantly improved the prevalence of helmet use or police repression in Kenya [11]. Elsewhere, however, the introduction of helmet promotion laws has had a positive impact [20-22]. In our survey, the prevalence of helmet use $(59.7 \%)$ was higher than in the above studies. This relatively high prevalence can be explained by the urban site of our observation and slightly by police sanction $(p<0,05$, table 4$)$. As shown in the Ghana studies, the prevalence of helmet use is higher in urban areas than outside the city $[3,4]$, probably due to police presence on urban roads. At home no driver had a helmet for the passenger; this implies that no passenger wears a helmet during traffic. This finding is also reported in studies conducted in Ghana, where only $1.9 \%$ to $3.7 \%$ of passengers wore helmets and often borrowed them from the driver [17,
18]; and in those conducted in Kenya, where 2.77 to $2.43 \%$ of passengers wore helmets [15]. The prevalence of helmet use is, however, very high in South-West Asia, particularly in Indonesia, where it is $89 \%$ [23]. Factors contributing to helmet non-wearing may be: a low level of knowledge of the risks and the importance of helmets as suggested by the Fadekemi O study [16], but in our context it is perhaps necessary to mention the laxity of the authorities in applying sanctions; two thirds $(69.3 \%)$ of our respondents were sanctioned without much deterrence. However, the majority of motorcycle taxi drivers were in favor of wearing a helmet (95.4\%) and punishing offenders (83.8\%). Fadekemi O also reported a favorable attitude towards helmet use among the majority, who in $67 \%$ approved of the strengthening of laws on helmet use [16].

Table 4. Wearing a safety helmet in modalities of school level, motorcycle ownership, seniority in motorcycle riding, police sanction history and accident history.

\begin{tabular}{|c|c|c|c|}
\hline & Wearing the helmet & Not wearing the helmet & P [KHI2] \\
\hline \multicolumn{3}{|c|}{ Road accident history } & 0.7 \\
\hline Yes & 95 & 62 & \\
\hline Never & 49 & 35 & \\
\hline \multicolumn{3}{|l|}{ School-level } & 0.9 \\
\hline None or low ${ }^{\mathrm{a}}$ & 24 & 36 & \\
\hline Medium or high ${ }^{b}$ & 73 & 108 & \\
\hline \multicolumn{3}{|c|}{ Previous police sanction for not wearing a helmet } & $0.03 *$ \\
\hline Yes $^{c}$ & 60 & 107 & \\
\hline No & 37 & 37 & \\
\hline \multicolumn{3}{|c|}{ Belonging to the motorcycle } & 0.09 \\
\hline Tenant & 27 & 55 & \\
\hline Owner & 70 & 89 & \\
\hline \multicolumn{3}{|c|}{ Seniority in motorcycle riding (years) ${ }^{\mu}$} & 0.1 \\
\hline $0-4$ & 51 & 93 & \\
\hline $5-10$ & 28 & 36 & \\
\hline $11-15$ & 13 & 9 & \\
\hline $16-20$ & 4 & 6 & \\
\hline \multicolumn{4}{|c|}{ Attitude to helmet use 0.1} \\
\hline Favorable & 95 & 135 & \\
\hline Unfavorable & 2 & 11 & \\
\hline
\end{tabular}

$\mathrm{a}=$ Elementary certificate, $\mathrm{b}=$ from first cycle brevet, $\mathrm{c}=$ verbal warning to other sanctions. $\mu=$ one motorcyclist didn't give his driving seniority.

*statistically significant.

This situation leads us to believe that educational and capacity building actions, and promotion of the law in the form of dialogue with drivers and the population are necessary. In road safety interventions, warning signs should be put up in places where "motorcycle taxis" are parked. However, raising awareness among motorcycle taxi drivers raises the issue of recognition of this activity by municipal and police authorities. This study therefore opens up the prospect of raising the authorities' awareness of the extent of this practice and the need to regulate it.

\section{Conclusion}

The activity of driving a "motorcycle taxi" is practiced by adult men. The prevalence of helmet use is low among them and almost nil among their passengers, exposing them to the risk of fatal head injuries. Despite a high level of knowledge and a favorable attitude towards the use of safety helmets. The promotion of the wearing of safety helmets should take into account the emergence of this type of public transport, in order to address awareness and coercive actions to them.

\section{Limitations of the Study and Outlook}

It was difficult to know the total number of drivers, as this activity is not yet organized, as no previous counts exist to constitute a reliable database. The study was limited to an area of Brazzaville. We plan to conduct a larger study on the observation of all motorcyclists on the road at several locations frequented to have a national prevalence of helmet use.

\section{Conflict of Interest}

The authors do not declare any conflict of interest or external funding. 


\section{Acknowledgements}

The authors would like to thank all the drivers who participated in the survey.

\section{References}

[1] Oluwadiya KS, Ogini LM, Olassinde A, Fadiaro SO. Motorcycle limb injuries in a developing country. West Afr J Med. 2004; 23: 42-7.

[2] Noukpo A. Les taxis-motos zemijan à Porto-Novo et Cotonou. Autre part. 2004; 4 (32): 135-48.

[3] Driver and Vehicle Licensing Authority. Total Number of Registered Vehicles in Ghana by Category. Accra, Ghana: Driver and Vehicle Leasing Authority; 2009.

[4] Kenya National Bureau Statistics. Statistical Abstract Nairobi. Kenya: Kenya National Bureau Statistics; 2012. 2012.

[5] Bachani AM, Koradio P, Herbert HK, Mogere S, Akungah D, Nyamari J, et al. Road traffic injuries in Kenya: the health burden and risk factors in two districts. Trafic Inj Prev. 13 (Supp11): 24-30.

[6] World Health Organization. Helmets: A Road Safety Manual for Decision Makers and Practitioners. WHO, Geneva, Switzerland.; 2006

[7] National Highway Traffic Safety Administration (NHTSA). Traffic Safety Facts: Motorcycle Helmet Use in 2008-Overall Results: Report No. DOT HS 811 044. Department of Transportation, Washington, DC. 2008.

[8] Elliott MA, Baughan CJ, Sexton BF. Errors and violations in relation to motorcyclists' crash risk. Accident Analysis and Prevention. 2007; 39 (3): 491-9.

[9] World Health Organization. Global Status Report on Road Safety 2013: Supporting a Decade of Action. [Internet]. 2013. Disponible sur: http://www.who.int/violence injury prevention/road safety.../2013/report/en/.

[10] Ekouele Mbaki HB, Bingui PDO, Elombila M, Mbou Essie DE, et al. Socio-Demographic Profile of Adults Admitted in Emergency for Brain Trauma Injuries at the University Hospital of Brazzaville (Congo). Open Journal of Modern Neurosurgery. 2019; 9: 43-48.

[11] Ferrando J, Plascencia A, Oros M, Borell C, Krauss JF. Impact of a helmet law on two-wheel motor vehicle crash mortality in a southern European urbanarea. Inj Prev. 2000; 6: 184-8.
[12] Rutledge R, Stutts J. The association of helmet use with the outcome of motorcycle crash injury when controlling for crash severity. Accid Anal Prev. 25: 347-53.

[13] Liu BC, Ivers R, Norton R, Boufous S, Blows S, Lo S. Helmets for preventing injury in motorcycle riders. The Cochrane Database of Systematic Reviews 2005. 2009; 4.

[14] Keng SH. Helmet use and motorcycle fatalities in Taiwan. Accident Analysis and Prevention. 2005; 37 (2): 349-55.

[15] Bachani AA, Hung YW, Mogere S, Akunga D, Nyamari J, Hyder AA. Helmet wearing in Kenya: prevalence, knowledge, attitude, practice and implications. Public Health. 144 (2017): S23-31.

[16] Oginni FO, Ugboko VI, Adewole RA. Knowledge, Attitude, and Practice of Nigerian Commercial Motorcyclists in the Use of Crash Helmet and other Safety Measures. Traffic Injury Prevention. 7 mai 2007; 8 (2): 137-41.

[17] Akaateba MA, Amoh-Gyimah R, Yakubu I. A cross-sectional observational study of helmet use among motorcyclists in Wa, Ghana. Accident Analysis \& Prevention. mars 2014; 64: 18-22.

[18] Ackaah W, Afukaar FK. Prevalence of Helmet Use Among Motorcycle Users in Tamale Metropolis, Ghana: An Observational Study. Traffic Injury Prevention. 22 sept 2010; 11 (5): $522-5$

[19] Organisation des nations unies pour l'éducation, la science et la culture. Atlas mondial de l'égalité des genres dans l'éducation ; 2012 [Internet]. 2012 [cité 21 nov 2019]. Disponible sur: https://apps.who.int/iris/bitstream/handle/10665/204409/9789 241565011_fre.pdf?sequence $=1$

[20] Maryrose J. The effects of a mandatory motorcycle helmet law on helmet use and injury patterns among motorcyclist fatalities. J Saf Res. 2008; 39 (4): 429-32.

[21] World Health Organization. Global status report on road safety. Geneva; 2015.

[22] Chiu WT, Kuo CY, HUng CC, Chen MT. The effect of theTaiwan motorcycle helmet use law on head injuries. Am J Public Health. 2000; 90 (5): 793-6.

[23] Corad P, Bradshaw R, et al. Helmets, injuries and cultural definitions: motorcycle injury in urban Indonesia. Accid Anal Prev. 1996; 28: 193-200. 